J. Beerten, J. Verveckken, and J. Driesen, "Comparison of three-level torque hysteresis controllers for direct torque control," Proc. IEEE EUROCON '09, St. Petersburg, Russia, May 18-23, 2009, pp. $1942-1947$.

Digital Object Identifier: $10.1109 /$ EURCON.2009.5167914

URL:

http://ieeexplore.ieee.org/xpl/articleDetails.jsp?tp=\&arnumber=5167914

(C) 2009 IEEE. Personal use of this material is permitted. Permission from IEEE must be obtained for all other users, including reprinting/ republishing this material for advertising or promotional purposes, creating new collective works for resale or redistribution to servers or lists, or reuse of any copyrighted components of this work in other works. 


\title{
COMPARISON OF THREE-LEVEL TORQUE HYSTERESIS CONTROLLERS FOR DIRECT TORQUE CONTROL
}

\author{
Jef Beerten, Student Member, IEEE, Jan Verveckken, Student Member, IEEE, \\ and Johan Driesen Member, IEEE
}

\begin{abstract}
In this paper, a comparison is made between different implementations of the three-level torque comparator for a Direct Torque Control (DTC) based induction motor drive. The DTC scheme controls stator flux and torque by means of hysteresis comparators, respectively a two-level control structure for the stator flux and a three-level comparator for the electromagnetic torque. The standard three-level hysteresis controller has a DC offset torque error. In this paper, an additive implementation is investigated in order to remove this DC offset error. The operational principles of the different implementations are compared based on continuous and discrete simulation results, which demonstrate the additional advantages of the additive structure in a discrete implementation of the control scheme.
\end{abstract}

Index Terms-Direct Torque Control, induction motor control, hysteresis comparator.

\section{INTRODUCTION}

Since its introduction, Direct Torque Control (DTC) has gained increasing interest from researchers all over the world. The standard DTC scheme [1], [2] uses hysteresis comparators for the control of both stator flux magnitude and electromagnetic torque. The flux control is achieved by a two-level comparator and a three-level structure is often preferred for the control of the torque since it enables the use of zero voltage vectors which allow a smooth torque reduction. Ideally, these controllers limit both torque and flux to the bounds imposed by the hysteresis bands. This results in a non-constant switching frequency. When the DTC scheme is implemented using digital controllers, the controlled quantities are no longer strictly limited to these bounds since the discrete scheme operates at a fixed sampling frequency. However, the discrete scheme will operate like an analog one if the hysteresis bounds are chosen sufficiently large [3].

In order to diminish the increased torque and flux ripple resulting from a discrete implementation, alternative control schemes were developed that do not use hysteresis comparators to control flux and torque. The incorporation of Space Vector Modulation (SVM) has shown to be an effective method to lower the ripples. In this case, an optimal reference voltage vector is calculated based on DTC principles and applied to the machine using SVM. In [4], the reference voltage

Jef Beerten, Jan Verveckken and Johan Driesen are with the Department of Electrical Engineering (ESAT), Division ELECTA, University of Leuven (K.U.Leuven), Kasteelpark Arenberg 10 bus 2445, 3001 Heverlee, Belgium (e-mail: jef.beerten@esat.kuleuven.be).

Jan Verveckken is funded by a research grant from the "Institute for the Promotion of Innovation through Science and Technology in Flanders (IWT-Vlaanderen)" is determined using a PI-controller for the torque and a deadbeat controller for the flux. Lascu et al. [5] developed a direct torque control strategy based on Sliding-Mode Control (SMC) and Space Vector Modulation (SVM).

However, SVM based schemes often use a transformation to a rotating reference frame combined with inverse motor models based on induction motor parameters in order to determine an optimal voltage vector. This makes them more complex and less robust to parameter variations than the basic DTC scheme, which only depends on the stator resistance.

Other DTC based control schemes often incorporate hysteresis comparators because of their robust control behavior and fast dynamic response. Romeral. et al [6] presented a scheme similar to the conventional DTC scheme, but with a Fuzzy Logic Modulator (FLM) to provide a variable duty cycle. In [7], a variable duty cycle is calculated using equations of the induction motor in order to enforce the torque within an asymmetric hysteresis band. In [8], a high-frequency dithering signal is superimposed on the torque error and flux error, which form the inputs of two hysteresis comparators.

In this paper, a comparison is made between different implementations of the torque hysteresis controller. After introducing the basic DTC principles and discussing the operation for forward and backward rotation, subsequent sections address the working principles of different implementations for the threelevel torque comparator. The classical implementation of the torque hysteresis controller used by Takahashi [2] results in a DC offset torque error. An additive hysteresis controller is investigated to eliminate this DC offset error. Furthermore, attention is paid on the controlling behavior of the different structures when DTC is implemented on a discrete-time base. Continuous and discrete simulations and experimental results demonstrate the improvements that can be made using an additive implementation of the torque controller instead of the classical structure.

\section{Direct Torque Control Principles}

\section{A. DTC basics}

Fig. 1 shows the basic DTC scheme, proposed by Takahashi [2]. All quantities are described in a stationary $\alpha \beta$-reference frame fixed to the stator. The stator voltage vector $\vec{u}_{s}$ and stator current vector $\vec{i}_{s}$ are calculated from the measured stator currents $i_{a b c}$, DC bus voltage $U_{d c}$ and gate signals $S_{a b c}$. The instantaneous values of the stator flux linkage $\vec{\psi}_{s}$ and the 


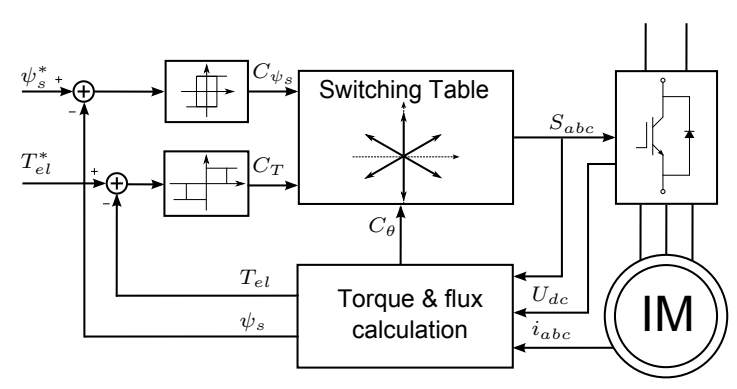

Fig. 1. Basic DTC scheme proposed by Takahashi [2]

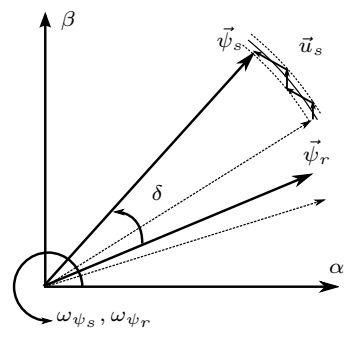

(a)

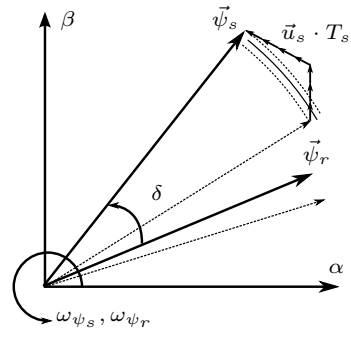

(b)
Fig. 2. DTC operation principles in a stationary $\alpha \beta$-reference frame: (a) continuous and (b) discrete implementation

electromagnetic torque $T_{e l}$ are calculated using (1) (2). In (2), $\times$ designates a vector product.

$$
\begin{aligned}
\vec{\psi}_{s} & =\int\left(\vec{u}_{s}-R_{s} \cdot \vec{i}_{s}\right) d t \\
T_{e l} & =\frac{3}{2} \cdot p \cdot\left(\vec{\psi}_{s} \times \vec{i}_{s}\right)
\end{aligned}
$$

The calculated magnitudes of both controlled quantities are thereafter compared to their respective reference values $\psi_{s}^{*}$ and $T_{e l}^{*}$ using hysteresis comparators, with torque and stator flux magnitude errors defined as $\Delta T_{e l}=T_{e l}^{*}-T_{e l}$ and $\Delta \psi_{s}=\psi_{s}^{*}-\psi_{s}$. In the basic implementation, a two-level hysteresis controller is used for the flux linkage and a three-level controller is used for the electromagnetic torque. The outputs $C_{\psi_{s}}$ and $C_{T}$, together with the sectant position of the stator flux linkage $C_{\theta}$, form the inputs of the switching table which selects the optimal inverter switching state during the next sample period. The electromagnetic torque can be rewritten as (3), with $L_{h}, L_{s}$ and $L_{r}$ respectively the mutual, stator and rotor inductance, $\sigma$ the Blondel leakage coefficient and $\delta$ the load angle from $\vec{\psi}_{r}$ to $\vec{\psi}_{s}$.

$$
\begin{aligned}
T_{e l} & =\frac{3}{2} \cdot \frac{p \cdot L_{h}}{\sigma L_{s} L_{r}} \cdot\left(\vec{\psi}_{r} \times \vec{\psi}_{s}\right) \\
& =\frac{3}{2} \cdot \frac{p \cdot L_{h}}{\sigma L_{s} L_{r}} \cdot \psi_{s} \cdot \psi_{r} \cdot \sin \delta
\end{aligned}
$$

Due to the large rotor time constant, the rotational speed $\omega_{\psi_{r}}$ of the rotor flux linkage $\vec{\psi}_{r}$ can be assumed to be constant on a small time scale. Under this assumption, $T_{e l}$ can be controlled by changing either $\psi_{s}$ or $\delta$. When the control scheme keeps $\psi_{s}$ constant, $T_{e l}$ can be controlled by varying the load angle $\delta$. Fig. 2 shows the control of the stator flux magnitude, the

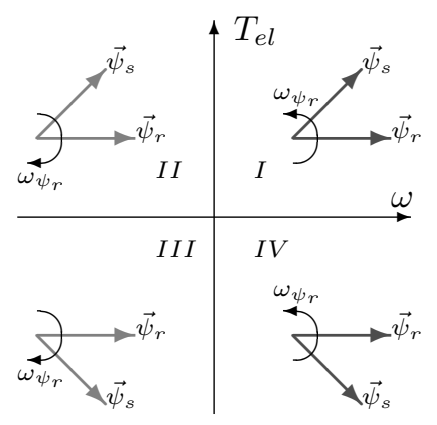

Fig. 3. DTC four quadrants operation

stator flux angle and therefore the load angle $\delta$ by applying the appropriate stator voltage vector $\vec{u}_{s}$, for a continuous (Fig. 2a) and discrete implementation (Fig. 2b).

\section{B. Four quadrant operation}

A distinction can be made between anticlockwise (forward) and clockwise (backward) rotation of the rotor flux vector $\vec{\psi}_{r}$, as shown in Fig. 3. Except for a very short transition period when $\vec{\psi}_{r}$ changes direction, the direction of $\omega_{\psi_{r}}$ is the same as the rotational direction of the machine. Transitions between quadrants $I \leftrightarrow I V$ and $I I \leftrightarrow I I I$ can be achieved very quickly since they involve no change of the rotation direction of $\vec{\psi}_{r}$.

If a voltage vector results in a forward rotation of the stator flux vector $\vec{\psi}_{s}$, it is said to be a forward voltage vector $\left(C_{T}=+1\right)$. On the contrary, when a voltage vector results in a backward rotation of $\vec{\psi}_{s}$, the vector is a backward voltage vector $\left(C_{T}=-1\right)$. The influence of a zero voltage vector $\left(C_{T}=0\right)$ on the torque is crucial in understanding the working principles of the hysteresis controllers.

In forward operation mode, an increase of $T_{e l}$ is realized by applying a forward voltage vector to the machine, whereas a zero voltage vector will result in a decrease. Furthermore, it is possible to achieve a fast torque decrease by applying a backward voltage vector. In backward operation mode, an increase of $T_{e l}$ is accomplished by a zero voltage vector and a decrease of $T_{e l}$ by a backward voltage vector. A forward voltage vector can be used to obtain a fast increase of $T_{e l}$.

The distinction between forward and backward operation is more important to the hysteresis controllers than the distinction between motor and generator mode. When the operation mode is left unaltered in the transition from one quadrant to another, the same path in the hysteresis comparator will be used. A transition between forward and backward operation is more complicated since it is dictated by a change of the effect of the zero voltage vector on the torque.

The motor behavior is described in a stator flux oriented rotating $d q$-reference frame to analyze this transition. The stator voltage equations can be written 
as (4) - (5). The torque equation reduces to (6).

$$
\begin{aligned}
u_{s d} & =R_{s} \cdot i_{s d}+\frac{d \psi_{s}}{d t} \\
u_{s q} & =R_{s} \cdot i_{s q}+\omega_{\psi_{s}} \cdot \psi_{s} \\
T_{e l} & =\frac{3}{2} \cdot p \cdot \psi_{s} \cdot i_{s q}
\end{aligned}
$$

In a simplified analysis of the control scheme neglecting the stator resistance voltage drop, a zero voltage vector is said to result in a momentary standstill of $\vec{\psi}_{s}$. Due to the dynamics of $\vec{\psi}_{r}$, this standstill results in a change of the load angle $\delta$ and therefore $T_{e l}$. With the stator resistance voltage drop in (1) taken into account, a zero voltage vector causes a slight decrease of the stator flux amplitude $\psi_{s}$. Moreover, (6) shows that a positive value of $T_{e l}$ implies a positive value of $i_{s q}$. Therefore (5) shows the application of a zero voltage vector for $T_{e l}>0$ also results in a small backward rotation of the $d q$-reference frame and thus of $\vec{\psi}_{s}$ when observed in a stationary $\alpha \beta$-frame.

According to (4) - (6), when $T_{e l}<0$ a zero voltage vector results in a decrease of $\psi_{s}$ on the one hand and a small forward rotation of the rotating $d q$-reference frame and thus of $\vec{\psi}_{s}$ in the $\alpha \beta$-frame on the other hand. The small rotation of $\vec{\psi}_{s}$ due to the stator resistance voltage drop is pointed towards $\vec{\psi}_{r}$.

The effect of this small rotation is important to deduce the effect of a zero voltage vector on the torque. The analysis will be confined to quadrants $I$ and $I V$. When a torque decrease is commanded in quadrant $I$, a zero voltage vector will be used. The stator voltage drop $R_{s} \cdot i_{s q}$ results in an additional torque decrease since it further reduces $\delta$. For quadrant $I V$ a zero voltage vector will also be used to obtain a decrease of $T_{e l}$ (thus an increase of $\left|T_{e l}\right|$ ). However, the result of the stator resistance voltage drop is a smaller torque decrease than one would expect when the voltage drop is omitted. When $\omega_{\psi_{r}}$ is diminishing (quadrant $I V$ ) and $i_{s q}$ is rather large, it will become impossible to reduce the torque using a zero voltage vector since the forward rotation of $\vec{\psi}_{s}$ due to $R_{s} \cdot i_{s q}$ will dominate over the forward rotation of $\vec{\psi}_{r}$. When this happens a transition will be made towards quadrant $I I I$. The controller then has to use the zero voltage vector to raise $T_{e l}$ and a backward voltage vector to lower $T_{e l}$.

\section{THREE-LEVEL TORQUE HYSTERESIS COMPARATOR}

The purpose of the torque hysteresis comparator is to limit the torque $T_{e l}$ to the bands imposed by the hysteresis controller. In this section, a detailed description of the hysteresis controllers is given. The different control structures lead to a different behavior under continuous and discrete implementation. Simulations are carried out on a standard $4 \mathrm{~kW}, 400 \mathrm{~V}, 50 \mathrm{~Hz}$ 4pole induction machine. In this section, the ability of the machine to track a reference torque value of $20 \mathrm{Nm}$ is investigated. The discrete simulations are carried out using a sampling frequency of $30 \mathrm{kHz}$, which is in the upper range of research based implementations but lower than the $40 \mathrm{kHz}$ used in industrial drives [9]. Furthermore a prediction scheme presented in [10] is implemented for the discrete simulations in to order to lower both torque and flux ripple. The prediction scheme removes the part of the ripples associated with the time delay caused by the processing of the data.

The ability of the different structures to diminish the DC offset torque error will be investigated. In most practical applications, DTC is used as an inner control loop of a variable speed motor drive. The torque reference value $T_{e l}^{*}$ is thereby provided by the outer speed control loop. A DC offset error can be compensated by the outer control loop by using a PI controller. However, higher accuracy of the inner control loop may result in better performance. In comparing the different implementations, sufficient attention will be paid on the discrete time behavior since most practical applications use digital controllers.

\section{A. Symmetric implementation}

The standard implementation of the torque hysteresis controller, used by Takahashi [2] and adapted in [3], [8], [11]-[15] is depicted in Fig. 4. The threelevel structure can be easily constructed by adding the output signals of two independent two-level hysteresis controllers, depicted in Figs. $4 \mathrm{a}-4 \mathrm{~b}$. The overall control structure is depicted in Fig. 4c. The control objective for forward operation mode of this structure can be summarized as (7). $B_{T}$ is the width of the hysteresis band.

$$
C_{T}= \begin{cases}1 & \text { if }\left|T_{e l}\right| \leq\left|T_{e l}^{*}\right|-B_{T} \\ 0 & \text { if }\left|T_{e l}\right| \geq\left|T_{e l}^{*}\right|\end{cases}
$$

and for backward operation mode as (8) [9].

$$
C_{T}=\left\{\begin{aligned}
-1 & \text { if }\left|T_{e l}\right| \geq\left|T_{e l}^{*}\right|+B_{T} \\
0 & \text { if }\left|T_{e l}\right| \leq\left|T_{e l}^{*}\right|
\end{aligned}\right.
$$

The overall control behavior results in a DC offset error on the torque (Fig. 5a). The controllers with outputs $C_{T, 1}$ and $C_{T, 2}$ have no overlap. Therefore, only one hysteresis comparator can have an active output at the same time and the operation of the two comparators is independent. Figs. 5a - 5b show only $C_{T, 2}$ and $C_{T, 1}$ are used in forward and backward operation respectively. When the operation mode changes from forward to backward rotation, a transition occurs and $C_{T, 1}$ instead of $C_{T, 2}$ will be used. This transition is caused by the changing effect of the zero voltage vector which moves $T_{e l}$ to the upper hysteresis band, as discussed in section II-B.

Although the backward voltage vectors $\left(C_{T}=-1\right)$ are not considered for a continuous forward operation mode, they can be used in a discrete implementation. When the torque excursion is detected after $T_{e l}$ exceeds the upper hysteresis band, a backward voltage vector will be used to reduce $T_{e l}$. Therefore, after lowering $\Delta T_{e l}$ using an active voltage vector, $\left[-B_{T}, 0\right]$ serves as 


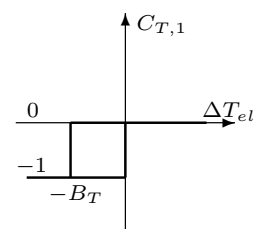

(a)

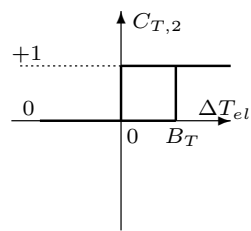

(b)

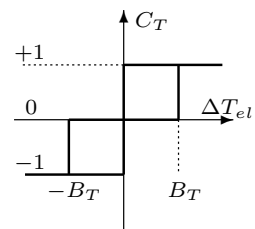

(c)
Fig. 4. Three-level symmetric hysteresis torque controller: (a) Backward operation, (b) Forward operation, (c) Global control structure

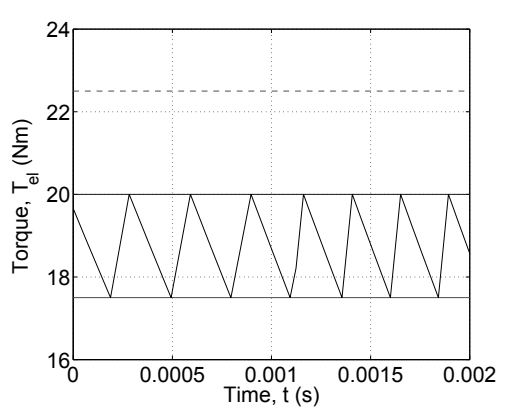

(a)

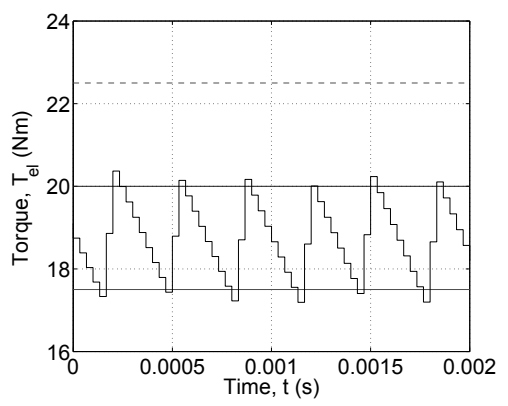

(c)

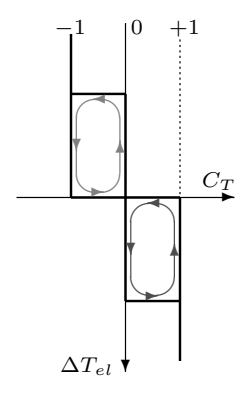

(b)

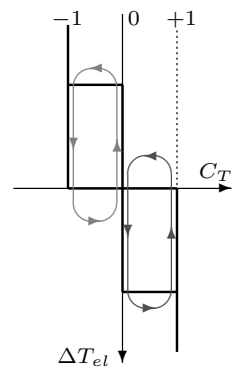

(d)
Fig. 5. Three-level symmetric hysteresis torque control: Torque reference tracking in continuous (a) and discrete (c) operation, torque error paths in continuous (b) and discrete (d) operation

a detection margin during which a zero voltage vector can be used to reduce $T_{e l}$ (Figs. $5 \mathrm{c}-5 \mathrm{~d}$ ). This detection margin is of importance in a discrete implementation. If the controlling objective is to reduce the torque using a zero voltage vector, a sufficiently large detection margin is desired. However, a large value of $B_{T}$ implies that the zero voltage vector will be applied for a long time period when a transition between a forward and backward operation occurs. According to (4), this causes the stator flux linkage magnitude $\psi_{s}$ to diminish, resulting in a demagnetization of the machine. Furthermore, $B_{T}$ is linked with the minimum torque ripple, which is normally chosen rather small. It is therefore hard to combine a large detection margin and a small torque ripple with this structure.

\section{B. Asymmetric implementation}

In order to reduce the DC offset error, the hysteresis comparators $C_{T, 1}$ and $C_{T, 2}$ from Fig. 4 can partly overlap [7], as shown in Fig. 6. Hereby, the reversal of $\Delta T_{e l}$ is shifted towards a non-zero value $\pm B_{i n}$. When a forward voltage vector is applied in forward

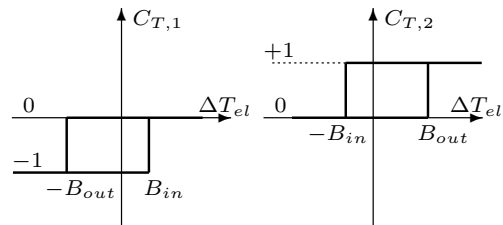

(a)

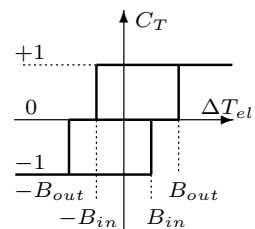

(c)
Fig. 6. Three-level asymmetric hysteresis torque controller: (a) Backward operation, (b) Forward operation (c), Global control structure

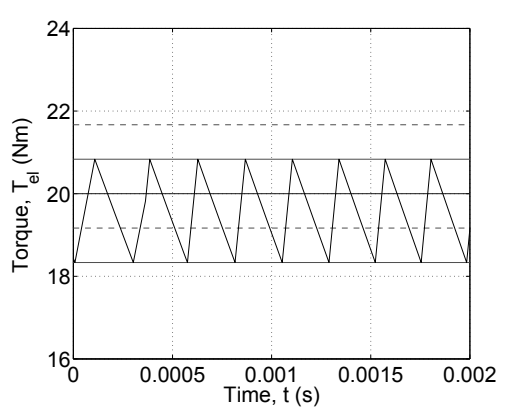

(a)

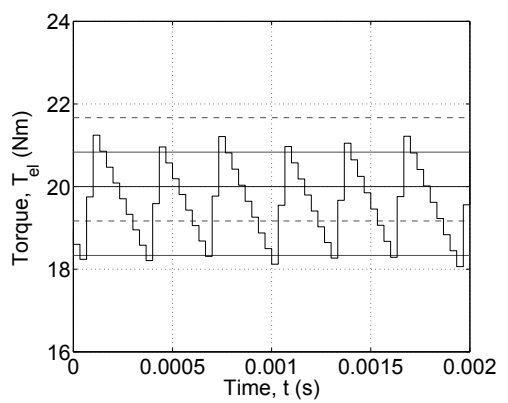

(c)

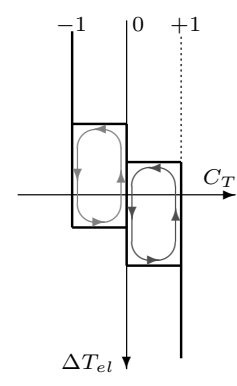

(b)

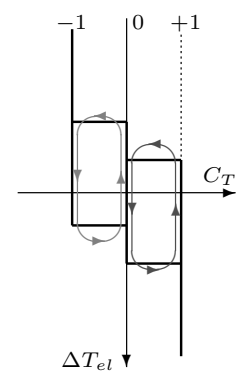

(d)
Fig. 7. Three-level asymmetric hysteresis torque control: Torque reference tracking in continuous (a) and discrete (c) operation, torque error paths in continuous (b) and discrete (d) operation

operation mode, $\Delta T_{e l}$ will move towards the switchoff value $-B_{\text {in }}$ of $C_{T, 2}$. Meanwhile, $C_{T, 1}$ remains 0 while $\Delta T_{e l}>-B_{\text {out }}$. For a continuous implementation, this will always be fulfilled, since $\Delta T_{e l}$ will not exceed the bounds imposed by $C_{T, 2}$. In this control structure, either $C_{T, 1}$ or $C_{T, 2}$ determines the final output of the controller, as with the symmetric implementation. The torque and torque error path for an continuous scheme are presented in Figs. $7 \mathrm{a}-7 \mathrm{~b}$.

In a discrete implementation the torque error $\Delta T_{e l}$ is no longer limited to the bounds imposed by the hysteresis controllers, as shown in Figs. 7c - 7d. When the excursion of $\Delta T_{e l}$ is not detected in time in forward operation mode, $\Delta T_{e l}$ will exceed $-B_{\text {out }}$ in Fig. 6c. The torque error $\Delta T_{e l}$ will then be driven towards $B_{i n}$ using a backward voltage vector. Finally, a zero voltage vector will be used to drive $\Delta T_{e l}$ towards $B_{\text {out }}$ if a detection takes place in $\left[B_{\text {in }}, B_{\text {out }}\right]$. As shown in Figs. 7a and 7c, providing an overlap of $B_{\text {in }}$ for both $C_{T, 1}$ and $C_{T, 2}$ results in a smaller DC offset on the torque. However, the DC offset can not be 


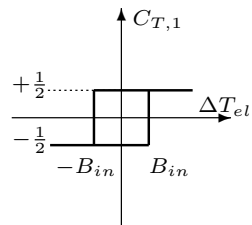

(a)

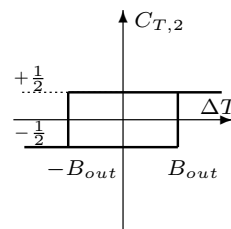

(b)

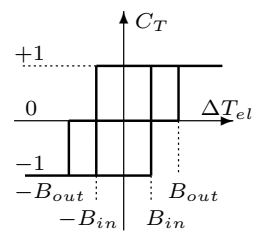

(c)
Fig. 8. Three-level additive hysteresis torque controller: (a) Inner comparator, (b) Outer comparator, (c) Global control structure

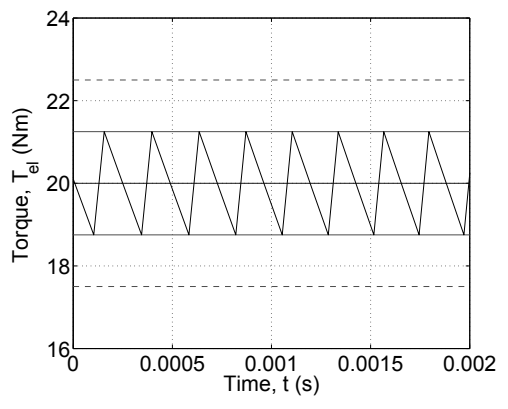

(a)

(c)

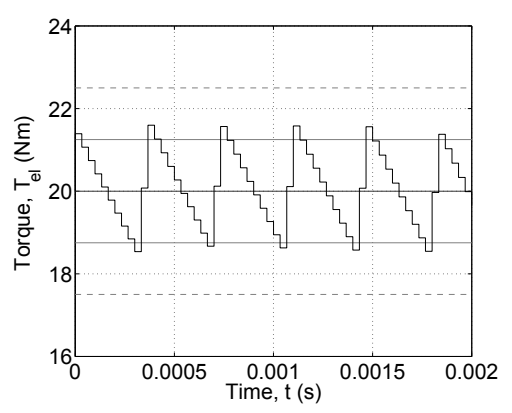

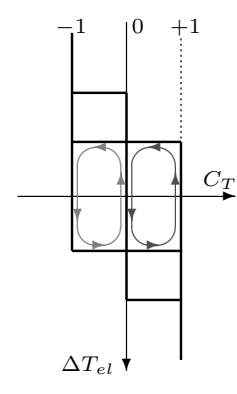

(b)

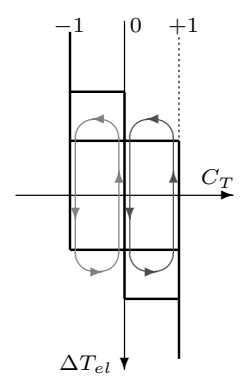

(d)
Fig. 9. Three-level additive hysteresis torque control: Torque reference tracking in continuous (a) and discrete (c) operation, torque error paths in continuous (b) and discrete (d) operation

totally eliminated. As a drawback, this overlap results in a smaller detection margin, which is diminished to $B_{\text {out }}-B_{\text {in }}$ compared to $B_{T}$ in the symmetric operation. It can be concluded that the DC offset, detection margin and torque error can not be set independently and a trade-off has to be made.

\section{Additive implementation}

In this section, the drawbacks such as a DC torque offset and the dependency of the detection margin on the torque hysteresis bounds will be eliminated by adding the outputs of two overlapping hysteresis controllers. This control structure is considered in [16] for the current control of a multilevel converter. In [17], this additive implementation is used to construct a hysteresis comparator with 5 different output signals for current control of a multilevel inverter. In the symmetric and asymmetric implementations from previous sections, either comparator $C_{T, 1}$ or $C_{T, 2}$ determined the final control behavior. When using an additive implementation with completely overlapping comparators, the output signal depends on both $C_{T, 1}$

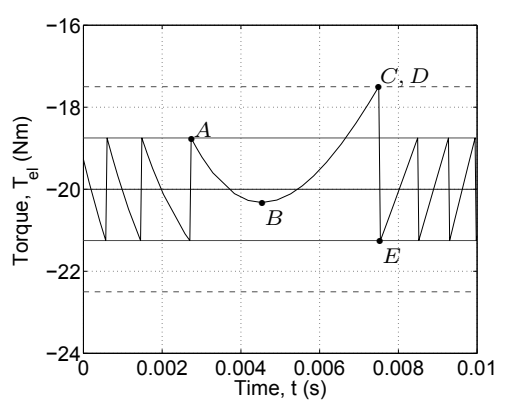

(a)

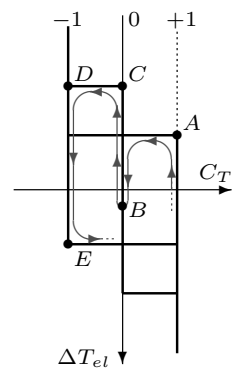

(b)
Fig. 10. Three-level additive hysteresis torque control, change of direction: (a) Torque reference tracking, (b) torque error paths

and $C_{T, 2}$, shown in Fig. 8 .

The additive implementation has two significant advantages over the comparator structures from previous sections. Firstly, this structure leads to a zero DC offset error, as shown in Figs. 9a - 9b. Secondly, the detection margin and torque ripple can be set independently as shown in Figs. 9c - 9d: The inner hysteresis bands $\pm B_{\text {in }}$ can be used to influence the torque ripple, whereas the detection margin is determined by $B_{\text {out }}-B_{\text {in }}$. The construction of the hysteresis is shown in Figs. $8 \mathrm{a}-8 \mathrm{c}$. The inner comparator $C_{T, 1}$ determines the controlling behavior in the additive structure. The output of the outer comparator $C_{T, 2}$ determines which vectors will be used to control the torque: When $C_{T, 2}$ is equal to $+\frac{1}{2}$, forward and zero voltage vectors will be applied to the machine, otherwise backward and zero voltage vectors are applied. In a continuous implementation, the inner comparator thus determines the torque excursion, whereas the outer comparator determines the change between forward and backward operation mode.

In the additive implementation, it is possible to combine a sufficient large detection margin with an adjustable torque ripple and zero torque DC offset whereas for the asymmetric implementation a tradeoff is needed in determining the overlap. Fig. 10 shows a change from forward rotation (quadrant $I V$ ) to backward rotation (quadrant $I I I$ ). At point $B$, the zero voltage vector can no longer diminish $T_{e l}$, as discussed in section II-B. This forces $T_{e l}$ towards the upper hysteresis band which triggers the outer comparator $C_{T, 2}$ (Fig. 8b). Thereafter the comparator will use zero and backward voltage vectors to respectively raise and lower $T_{e l}$. When the scheme is implemented on a discrete time base (Figs. 9c-9d), $B_{\text {out }}-B_{\text {in }}$ determines the detection margin. A large detection margin incorporates some disadvantages when a change in direction occurs, since the zero voltage vector will be applied quite long in order to trigger the outer hysteresis band. This causes the machine to demagnetize and results in a stator current increase when active voltage vectors are applied thereafter. In [18] a time-based three-level hysteresis comparator is proposed for current control that makes use of the slope of the current error to keep 


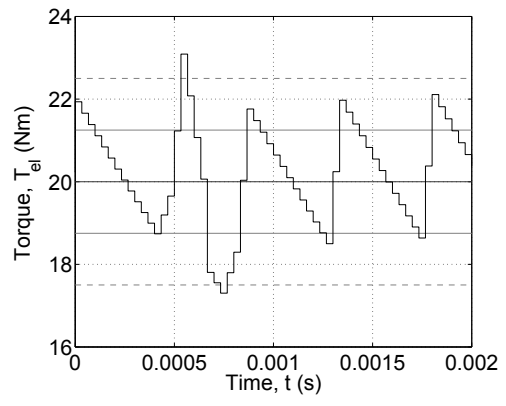

(a)

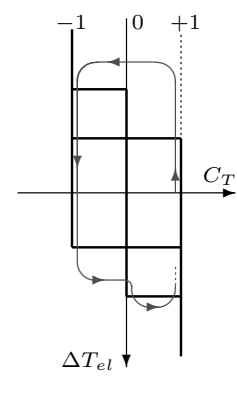

(b)
Fig. 11. Three-level additive hysteresis torque control, application of a backward voltage vector: (a) Torque reference tracking, (b) torque error paths

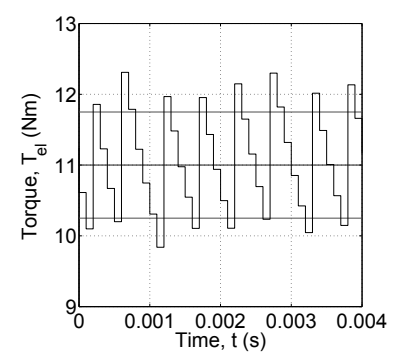

(a)

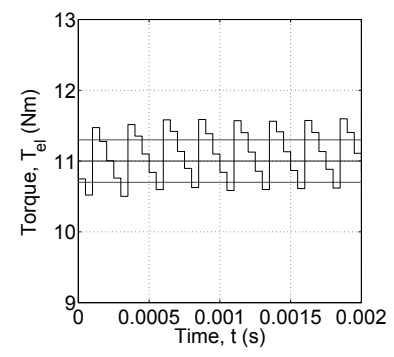

(b)
Fig. 12. Three-level additive hysteresis torque control: Experimental results with sampling frequency (a) $10 \mathrm{kHz}$ and (b) $20 \mathrm{kHz}$

the error within the inner hysteresis. During transient conditions, the extreme inverter stages are still used. However, time-based hysteresis controllers show lower robustness than multiple hysteresis controllers.

Another drawback of using a large detection margin is observed when a backward voltage vector is applied in forward rotation mode, as shown in Fig. 11. Using a backward voltage vector to lower $T_{e l}$ in forward operation results in a torque excursion of more than $2 B_{\text {out }}$. The previous structures will force the torque towards the outer lower hysteresis bound as well when a backward voltage vector is applied in forward operation. However, they can not independently control the detection margin and minimum torque ripple.

An experimental validation of the additive structure was carried out using the Triphase inverter platform [19]. The experimental set-up includes a $4 k \mathrm{~W}, 230 \mathrm{~V}$, $50 \mathrm{~Hz}$, 2-pole standard induction machine. The prediction scheme presented in [10] compensates for the time delay caused by the data processing. Experimental results for sampling frequencies of $10 \mathrm{kHz}$ and $20 \mathrm{kHz}$ are shown in Fig. 12.

\section{CONCLUSION}

A comparison between different three-level hysteresis controllers was presented, starting from a description of the dynamic behavior of the DTC scheme. The additive hysteresis controller shows significant advantages over the symmetric and asymmetric structure. Continuous and discrete simulation results show the possibilities of the additive implementation to eliminate the DC offset torque error. Furthermore, minimum torque ripple and detection margin can be set independently, which offers an additional benefit when the scheme is implemented on a discrete time base.

\section{REFERENCES}

[1] M. Depenbrock, "Direct self-control (DSC) of inverter-fed induction machine," IEEE Trans. Power Electron., vol. 3, no. 4, pp. 420-429, Oct. 1988.

[2] I. Takahashi and T. Noguchi, "A new quick-response and highefficiency control strategy of an induction motor," IEEE Trans. Ind. Appl., vol. IA-22, no. 5, pp. 820-827, Sep. 1986.

[3] G. S. Buja and M. P. Kazmierkowski, "Direct torque control of PWM inverter-fed ac motors - a survey," IEEE Trans. Ind. Electron., vol. 51, no. 4, pp. 744-757, Aug. 2004.

[4] K. B. Lee, F. Blaabjerg, and T. W. Yoon, "Speed-sensorless DTC-SVM for matrix converter drives with simple nonlinearity compensation," IEEE Trans. Ind. Appl., no. 6, pp. 1639-1649, Nov./Dec. 2007

[5] C. Lascu, I. Boldea, and F. Blaabjerg, "Very-low-speed variable-structure control of sensorless induction machine drives without signal injection," IEEE Trans. Ind. Electron., vol. 41, no. 2, pp. 591-598, Mar./Apr. 2005.

[6] L. Romeral, A. Arias, E. Aldabas, and M. Jayne, "Novel direct torque control (DTC) scheme with fuzzy adaptive torque-ripple reduction," IEEE Trans. Ind. Electron., vol. 50, no. 3, pp. 487492, Jun. 2003.

[7] V. Ambrožič, G. S. Buja, and R. Menis, "Band-constrained technique for direct torque control of induction motor," IEEE Trans. Ind. Electron., no. 4, pp. 776-784, Aug. 2004.

[8] T. Nogichu, M. Yamamoto, S. Kondo, and I. Takahashi, "Enlarging switching frequency in direct torque-controlled inverter by means of dithering," IEEE Trans. Ind. Appl., vol. 35, no. 6, pp. 1358-1366, Nov./Dec. 1999.

[9] P. Vas, Sensorless Vector and Direct Torque Control, ser. Monographs in Electrical and Electronic Engineering. New York: Oxford University Press, 1998.

[10] J. Beerten, J. Verveckken, and J. Driesen, "Prediction-based ripple reduction in direct torque control of an induction machine," in Proc. IEEE ICEM '08, Villamoura, Portugal, Sep. 6-9 2008.

[11] A. Jidin, N. R. N. Idris, and A. H. M. Yatim, "Study on stability and performance of DTC due to stator resistance variation," in Proc. IEEE SCOReD 2007, Permata Bangi, Malaysia, Dec. 11-12 2007, pp. 1-6.

[12] D. Casadei, F. Profumo, G. Serra, and A. Tani, "FOC and DTC: two viable schemes for induction motors torque control," IEEE Trans. Power Electron., vol. 17, no. 5, pp. 779-787, Sep. 2002.

[13] M. P. Kazmierkowski and P. Wojcik, "Reliable direct torque control with flux vector modulation (DTC-FVM) for ac motors," in Proc. IEEE SDEMPED 2007, Cracow, Poland, Sep. 6-8 2007, pp. 191-196.

[14] N. R. N. Idris and A. H. M. Yatim, "Direct torque control of induction machines with constant switching frequency and reduced torque ripple," IEEE Trans. Ind. Electron., vol. 51, no. 4, pp. 758-767, Aug. 2004.

[15] R. Bojoi, F. Farina, G. Griva, F. Profumo, and A. Tenconi, "Direct torque control for dual three-phase induction motor drives," IEEE Trans. Ind. Appl., vol. 41, no. 6, pp. 1627-1636, Nov./Dec. 2005.

[16] P. Loh, G. Bode, and P.-C. Tan, "Modular hysteresis current control of hybrid multilevel inverters," IEE Proc.-Electr. Power Appl., vol. 152, no. 1, pp. 1-8, Jan. 2005.

[17] J. F. Silva, N. Rodrigues, and J. Costa, "Space vector alphabeta sliding mode current controllers for three-phase multilevel inverters," in IEEE PESC 2000, vol. 1, Galway, Ireland, Jun. 18-23 2000, pp. 133-138.

[18] P. C. Loh, G. H. Bode, D. G. Holmes, and T. A. Lipo, "A time-based double-band hysteresis current regulation strategy for single-phase multilevel inverters," IEEE Trans. Ind. Appl., vol. 39, no. 3, pp. 883-892, May/Jun. 2003.

[19] http://www.triphase.com. 